doso en la 1

ar ejemplos a

is funcionalidac uso, dependiende encarnan los conceptos detr por e $\Lambda$ influ
$\mathrm{Pe}$ infin:

Las formas $d r$ oceso de sig ialidad .

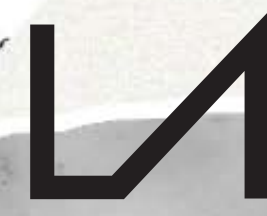

R E V I S A
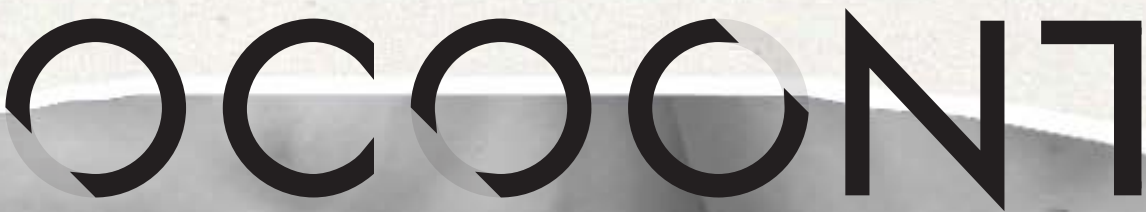

D $E$

No $6 \cdot 2019 \cdot$ ISSN 2386-8449

"El producto del diseñador es un proyecto, el estado previo de un objeto", Entrevista con Norberto Chaves, por Fernando Infante

El papel de la investigación y la teoría en diseño. Una conversación abierta, por Fernando Infante y María Jesús Godoy

UT PICTURA POESIS

Abandonar la escritura. Poesía experimental y manifiesta, Ignacio Gómez de Liaño

PANORAMA: FILOSOFÍA DEL DISEÑO Sección coordinada por Fernando Infante y María Jesús Godoy

Pensar el diseño, Fernando Infante y María Jesús Godoy (Coordinadores)

TEXTOS INVITADOS

Estatus y estado del điseño más allá del objeto, Pedro Medina Reinón

Mar de Nubes, Cuerpo de Cristal, Dionisio González

ARTÍCULOS

Understanding Design Aesthetics beyond Functional Beauty accounts, Lucía Jiménez Sánchez

Estética y diseño industrial: debates y controversias, Joan M. Marín

Del ornamento al delito. El diseño y la sociedad en Charles Baudelaire y Adolf Loos, Jorge López Lloret

When is Architecture not Design? Saul Fisher

Diseño y habitabilidad: una aproximación basada en los lenguajes de patrones, Antonio Hidalgo Pérez

Marcel Breuer: un diseñador global. Experiencias en el ámbito de la vivienda prefabricada, Salvador J. Sanchis, Ignacio Peris y Pedro Ponce Diseño y artes escénicas: el papel de Oskar Schlemmer en Das Triadische Ballett y la actualidad de la Bauhaus, Milagros García Vázquez Lo performativo en prácticas de arte y diseño actuales vinculadas a procesos de innovación social. El caso de La Venezia che non si vede y de La borda, Tània Costa Gomez

Articulaciones de la estética y el diseño. El caso de la evaluación a partir de la investigación dirigida en la carrera de diseño escénico de la Universidad de las Artes de Cuba, Mara Rodríguez Venegas y Xiomara Romero Rojas

SUPLEMENTO

El diseño, la ciudad y un lápiz de labios, Mercedes Espiau, Mar García Ranedo y Alejandro Rojas mas. 


\section{UつCつCNTE}

No $6 \cdot 2019 \cdot \operatorname{ISSN} 2386-8449 \cdot$ DOI 10.7203/LAOCOONTE.5.15381

https://ojs.uv.es/index.php/LAOCOONTE/index

COORDINACIÓN EDITORIAL

Anacleto Ferrer (Universitat de València)

Francesc Jesús Hernàndez i Dobon (Universitat de València)

Fernando Infante del Rosal (Universidad de Sevilla)

SECRETARÍA DE REDACCIÓN

Lurdes Valls Crespo (Universitat de València)

Vanessa Vidal Mayor (Universitat de València)

COMITÉ DE REDACCIÓN

Tamara Djermanović (Universitat Pompeu Fabra), Rosa Fernández Gómez (Universidad de Málaga), Anacleto Ferrer (Universitat de València), Ilia Galán (Universidad Carlos III), Ana María García Varas (Universidad de Zaragoza), María Jesús Godoy (Universidad de Sevilla), Fernando Infante del Rosal (Universidad de Sevilla), Miguel Ángel Rivero (Universidad de Sevilla), Miguel Salmerón (Universidad Autónoma de Madrid), Gerard Vilar (Universitat Autònoma de Barcelona).

COMITÉ CIENTÍFICO INTERNACIONAL

Rafael Argullol* (Universitat Pompeu Fabra), Luis Camnitzer (State University of New York), José Bragança de Miranda (Universidade Nova de Lisboa), Bruno Corà (Università di Cassino), Román de la Calle* (Universitat de València), Eberhard Geisler (Johannes Gutenberg-Universität Mainz), José Jiménez* (Universidad Autónoma de Madrid), Jacinto Lageira (Université Paris 1 Panthéon-Sorbonne), Bernard Marcadé (École Nationale Supérieure d'Arts de Paris-Cergy), Elena Oliveras (Universidad de Buenos Aires y Universidad del Salvador), Pablo Oyarzun (Universidad de Chile), Francisca Pérez Carreño* (Universidad de Murcia), Bernardo Pinto de Almeida (Faculdade de Belas Artes da Universidade do Porto), Luigi Russo (Università di Palermo), Georges Sebbag (Doctor en Filosofía e historiador del surrealismo), Zoltán Somhegyi (University of Sharjah, United Arab Emirates), Robert Wilkinson (Open University-Scotland), Martín Zubiria (Universidad Nacional de Cuyo). *Miembros de la Sociedad Española de Estética y Teoría de las Artes, SEyTA

\begin{tabular}{lll}
\hline DIRECCIÓN DE ARTE & REVISIÓN DE TEXTOS & TRANSCRIPCIÓN DE TEXTOS \\
El golpe. Cultura del entorno & Antonio Cuesta & Álvaro G. Serna
\end{tabular}

(cc) BY Excepto que se establezca de otra forma, el contenido de esta revista cuenta con una licencia Creative Commons Atribución 3.0 España, que puede consultarse en http://creativecommons.org/licenses/by/3.0/es/deed.es

EDITA

\section{SEyTA.}

CON LA COLABORACIÓN DE

\begin{tabular}{|c|c|c|c|}
\hline $\begin{array}{l}\text { VNIVERSITAT } \\
\text { ID VALENCIA } \\
\text { Institut a Creativitat } \\
\text { i|nnovacions Educatives }\end{array}$ & $\begin{array}{l}\text { VNIVERSITAT } \\
\text { IE ÖVALENCIA Departament de Filosofia }\end{array}$ & 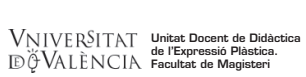 & \\
\hline $\begin{array}{l}\text { DEPARTAMENTO DE ESTÉTICA } \\
\text { E HISTORIA DE LA FILOSOFIA }\end{array}$ & $\frac{\text { UAW }}{\frac{\text { UNIVERSIDAD AUTONOMA }}{\text { DE MADRID }}}$ & $\begin{array}{l}\text { AB } \\
\text { Universitat Autònoma } \\
\text { de Barcelona }\end{array}$ & 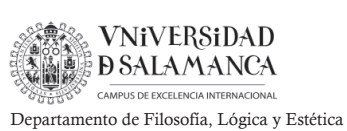 \\
\hline
\end{tabular}

LAOCOONTE aparece en los catálogos: 


\section{LつCつCN7E}

"Cuanto más penetramos en una obra de arte más pensamientos suscita ella en nosotros, y cuantos más pensamientos suscite tanto más debemos creer que estamos penetrando en ella".

G. E. Lessing, Laocoonte o los límites entre la pintura y la poesía, 1766.

Vo hay cól.

létodo, de pen.

:ión en general. Ith

zar la forma para el $\mathrm{n}$.

eptual por las orígenes

la, el objeto, la exposición

storia, porque existe en el $\mathrm{m}$

das sus raíces. Desde alli cc _. panoram

n conceptual y donde el émencia del con 'iseñado, como es el a al objeto y el di $\begin{array}{ll}\text { igen } \mathrm{de}^{\text {to }} \text { la inmer } & \text { tolvidada, o comc } \\ \text { trozo de madera ar }\end{array}$ a manera dorm comunicar ene nundo. Seguin? sngo en manos te el método $C$ les. A partir c teria prima $\mathrm{p}_{\mathbf{c}}$

'xto se puede:

¿ño, en proyea

amientos de $\mathrm{u}$

a conscie-

.)

en la publicación jue "plos de la impor te las nalidades porqu ura un ${ }^{2}$ diendo de qui zenerar $\mathrm{u}$ ción de nr? lne

in-

n-

is.

le http:,

le crear visualidades. A partir de.

ellas la propia materia prima para un en que desde un texto se puede generar $u_{11}$ i

Pensar en diseño, en proyección de nue

posibles comportamientos de una colecti

presente como una consciencia del hecho que estamos elaborando, significac

nuestro entorno (..)

Cardoso, R. C. Rafael. (2014). Design para um mundo complexo. Sãc asil: Cosac Naify. 


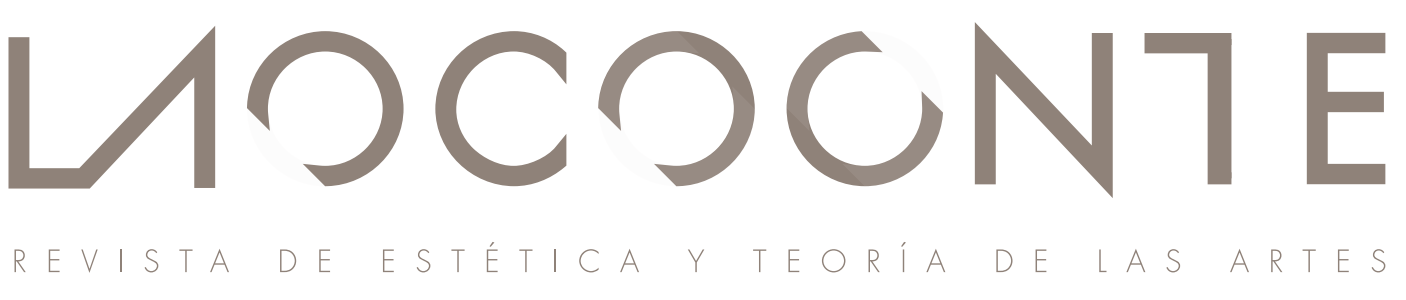

$\mathrm{N}^{\circ} 6 \cdot 2019$

PRESENTACIÓN

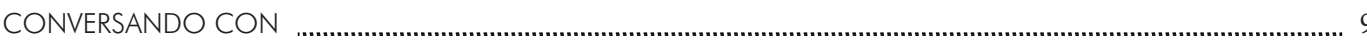

"El producto del diseñador es un proyecto, el estado previo de un objeto", Entrevista con Norberto Chaves,

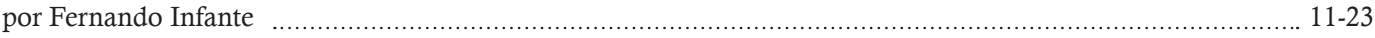

El papel de la investigación y la teoría en diseño. Una conversación abierta, por Fernando Infante

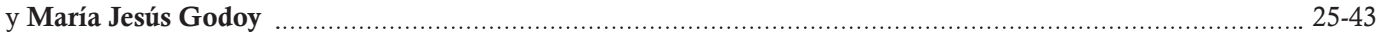

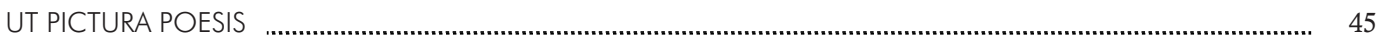

Abandonar la escritura. Poesía experimental y manifiesta, Ignacio Gómez de Liaño ................................................ 47-95

Imágenes de Laocoonte n. 6, de Isadora Gonzaga ................................................................................................... 96-97

PANORAMA

FILOSOFÍA DEL DISEÑO

Pensar el diseño, Fernando Infante y María Jesús Godoy (Coordinadores) .............................................. 101-105

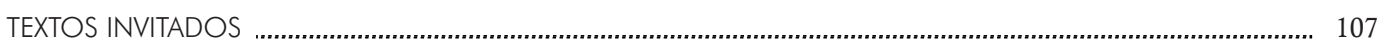

Estatus y estado del diseño más allá del objeto, Pedro Medina Reinón . ................................................... 109-125

Mar de Nubes. Cuerpo de Cristal, Dionisio González .............................................................................. 127-133

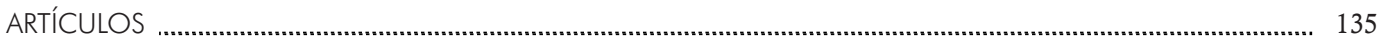

Understanding Design Aesthetics beyond Functional Beauty accounts, Lucía Jiménez Sánchez ................. 137-149

Estética y diseño industrial: debates y controversias, Joan M. Marín _...................................................... 150-164

Del ornamento al delito. El diseño y la sociedad en Charles Baudelaire y Adolf Loos, Jorge López Lloret ... $165-182$

When is Architecture not Design? Saul Fisher ……............................................................................. 183-198

Diseño y habitabilidad: una aproximación basada en los lenguajes de patrones, Antonio Hidalgo Pérez ...... 199-215

Marcel Breuer: un diseñador global. Experiencias en el ámbito de la vivienda prefabricada,

Salvador José Sanchis, Ignacio Peris y Pedro Ponce

Diseño y artes escénicas: el papel de Oskar Schlemmer en Das Triadische Ballett y la actualidad de la Bauhaus, Milagros García Vázquez

Lo performativo en prácticas de arte y diseño actuales vinculadas a procesos de innovación social.

El caso de La Venezia che non si vede y de La borda, Tània Costa Gomez

Articulaciones de la estética y el diseño. El caso de la evaluación a partir de la investigación dirigida en la carrera de diseño escénico de la Universidad de las Artes de Cuba, Mara Rodríguez Venegas

y Xiomara Romero Rojas

SUPLEMENTO 
Walter Gropius. La vida del fundador de la Bauhaus, Jorge Martínez Alcaide

¿Qué significa pensar la política desde la estética? Àger Pérez Casanovas

Ideologías estéticas en los orígenes de la pintura moderna, José Luis Plaza Chillón 300-303

Sobre a estética, Luis Carlos Pereira

Músicas populares. Sociedad y territorio: Sinergias entre investigación y docencia, Mar Aleixandre Badenes.

307-309

La necesidad de la mirada antropológica sobre la literatura, Pablo de Benito David

A propósito de Chandler, o la novela policíaca como tratado filosófico, Juan Evaristo Valls Boix

Videre aude!, Anacleto Ferrer

La inaplazable memoria del dolor y el sufrimiento, Antonio Notario Ruiz

La alargada sombra de la pintura, Raquel Baixauli

Sondear la maravilla, Juan Evaristo Valls Boix

... Y lo sabes, Marc Hernández Montoro

Arqueologías de la modernidad en las artes. Ensayo estético, Carlota Fernández-Jáuregui Rojas

Estética de la Instalación, Luis Cemillán Casis

La Herencia de otra época, María Jesús Godoy Domínguez

Del Theatrum Mundi al Gran Vidrio, Miguel Salmerón Infante

Imágenes de Isadora Gonzaga.

Fotografía de portada de Tamara Djermanovic intervenida por Isadora Gonzaga.

Los coordinadores de la sección Panorama: Filosofia del diseño agradecen

a Antonio Molina Flores su colaboración. 
ner.

llobj vidada, o de ma la publica. los de la im nalidades po ndientn $\mathrm{A}$ -
, la

que e.

usdño, si nn

ज. " da yara el mu tual y d

or enc or las orígenes un tmo, fía del diseño,

rpintero que'curra la forma de

eña Desige para un mundo complexo, de los bienes producidos por el hombre :tores subjetivos también influyen en su

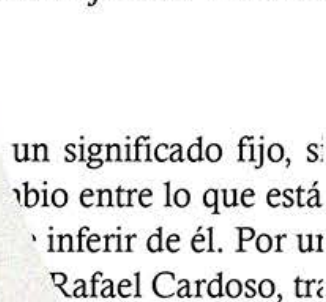

Rafael Cardoso, tri

No hay cómo no e método, de pensa 1, donde la reación en geperal. salizar la forma pa. rue amb ${ }_{\text {Snceptual por }}{ }^{1}$

$$
\text { -rola ol } n^{\prime}
$$

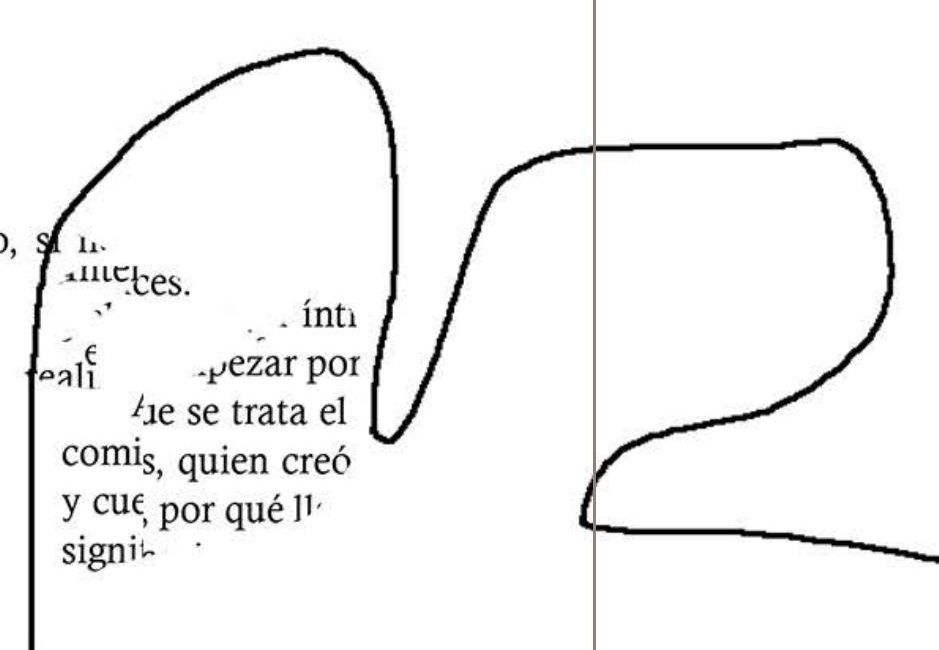

LOCOCNTE

PANORAMA: FILOSOFÍA DEL DISEÑO

Fernando Infante del Rosal y María Jesús Godoy Domínguez

(Coordinadores) 
- ormas y de rapo.

eso de un labor íntimo, un udo puede empezar por una inves 'dos: de que se trata el libro, el cu jió, que es, quien creó y por qué, ble o aún, por qué llama así, donı del pensamiento y intento a lle: Cual es el ambiente que cerca e ico. cuáles son los símholos aı

de una filosofía del diseño, si r e construcción de formas y de exponer el proceso de un labor í o sensible. Todo puede empezar los significados: de que se trata h, donde surgió, que es, quien creó y po mundo sensible o aún, por qué llama as cojo el hilo del pensamiento y intentc está ubicado. Cual es el ambiente que $\mathrm{g}$ anorama político, cuáles son los símb el concepto. Gradualmente, el conten y el diseñador encarna el papel de ur como un carpintero que toma la forr
LAU1 L11 glilla1. 111 n un sigizar la forma para e] ede inferifeptual por las orígt “. (Rafabla, el objeto, la exp istoria, porque exist y gradua adas sus raíces. De: en conceptual y do sible. $D$ : $r$ diseñado, como do, las icevolando la inman propio pri diseñar, a forma al prima e lengua olvi ese textos nrncesr a un trnzo ue construí ese discurso, he hecho de ara un reconfiguración de significado en para ilustrar... (en construccion) antiguas formas, es lanzar al mundo 1. La responsabilidad aquí se hace tamos elaborando, significados para

am mundo complexo. São Paulo,

1 agosto). Significado. Recuperado 1 br/significado/

\section{ИつCつCN7E}

PANORAMA: FILOSOFÍA DEL DISEÑO ARTÍCULOS 
- ormas y de rapon

aso de un labor íntimo, un udo puede empezar por una inves 'dos: de que se trata el libro, el cu rió, que es, quien creó y por qué, ble o aún, por qué llama así, donı del pensamiento $\mathrm{y}$ intento a lle Cual es el ambiente que cerca e ticn. cuáles son los símbolos a

de una filosofía del diseño, si r e construcción de formas y d $\epsilon$ exponer el proceso de un labor í o sensible. Todo puede empezar. los significados: de que se trata 1, donde surgió, que es, quien creó y po mundo sensible o aún, por qué llama as cojo el hilo del pensamiento y intento está ubicado. Cual es el ambiente que $q$ anorama político, cuáles son los símb lel concepto. Gradualmente, el conten y el diseñador encarna el papel de u somo un carpintero que toma la forr

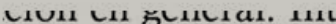
un signizar la forma para e] ambio eni ede inferieptual por las oríge n ". (Rafaəla, el objeto, la exp y gradua istoria, porque exist n danza adas sus raíces. De: en conceptual y do] sible. Dis $r$ diseñado, como do, las icevolando la inmanı ropio pri diseñar, $r$ ¥ forma al prima e lengua olvi

ese textos nrncesr a un trnzo ue construí ese discurso, he hecho de ara un reconfiguración de significado en para ilustrar... (en construccion) antiguas formas, es lanzar al mundo 1. La responsabilidad aquí se hace stamos elaborando, significados para

um mundo complexo. São Paulo,

1 agosto). Significado. Recuperado 1 $\mathrm{br} /$ significado/ 


\title{
Articulaciones de la estética y el diseño. El caso de la evaluación a partir de la investigación dirigida en la carrera de Diseño Escénico de la Universidad de las Artes de Cuba
}

\author{
Aesthetic and design joints. The case of the evaluation based \\ on the research conducted in the Scenic Design career of the \\ University of the Arts of Cuba
}

\author{
Mara Rodríguez Venegas ${ }^{*}$ Xiomara Romero Rojas ${ }^{* *}$
}

\section{Resumen}

En este texto analizamos el papel de la evaluación a partir de la investigación dirigida (ID) en la enseñanza-aprendizaje de la Estética en la carrera de Diseño Escénico. Para ello ubicamos algunas notas como antecedentes de la ID, indagamos en el concepto de formación estética como claves de esta propuesta, y por último, valoramos la aplicación de esta metodología a través de trabajos de jóvenes de dicha carrera. Concluimos con que la implementación de la evaluación como ID permite la fundamentación de los trabajos de los estudiantes acorde al entorno cultural y social que los rodea.

Palabras claves: Formación estética, valores estéticos, investigación dirigida, enseñanza, diseño escénico

\begin{abstract}
In this text we analyze the role of evaluation based on directed research (ID) in the teaching-learning of Aesthetics in the career of Scenic Design. For this we place some notes as background of the ID, we inquire into the concept of aesthetic training as keys to this proposal, and finally, we value the application of this methodology through the work of young people of said career. We conclude that the implementation of the evaluation as an ID allows the foundation of student work according to the cultural and social environment that surrounds them.
\end{abstract}

Key words: Aesthetic training, aesthetic values, directed research, teaching, stage design

La única manera de prepararse para la vida social es participar en la vida social.

John Dewey

\section{Introducción}

El aprendizaje y una enseñanza de la Estética a través de la Investigación Dirigida (ID en adelante), debe impulsar estrategias del trabajo científico entre los estudiantes.

* CIESAS Occidente. Guadalajara, Jalisco, México. mararv84@gmail.com

** Universidad de las Artes, La Habana, Cuba.xromerorojas@gmail.com Artículo recibido: 8 de julio de 2019; aceptado: 19 de octubre de 2019 
Resulta pertinente distanciarse del proceso educativo de manera vertical para entenderlo de forma horizontal, desde una perspectiva dinámica y relacional donde ambas partes aprenden. Esto resignifica el papel de ambos sujetos (estudiante y profesor) para desarrollar estrategias pedagógicas en la que la investigación no está separada de la enseñanza, sino que es parte de ella.

La evaluación a partir de la ID constituye nuestra propuesta pedagógica para la enseñanza de la Estética a los estudiantes de Diseño Escénico de la Universidad de las Artes $^{1}$ de Cuba. Ella muestra una cercana relación con las metodologías de Aprendizaje Basado en la Investigación (ABI en adelante) desarrolladas por algunos autores entre los que destaca Ernest Boyer (1990). También se relacionan de manera cercana con la corriente del constructivismo pedagógico en la cual se provee a los estudiantes de las herramientas pertinentes para dar soluciones problemas de investigación. Si bien han existido diferentes formas de aplicar el ABI, en este texto hacemos referencia a la ID que desde nuestra visión mantiene cercanía con la investigación guiada del ABI considerando algunos cambios. A pesar de que esta última metodología ha tenido detractores, para la enseñanza de la Estética resulta positiva para el proceso pedagógico porque propicia un acercamiento más íntimo entre la reflexión estética y la praxis del diseño. Esto se debe a que según nuestro criterio la evaluación a partir de la ID, guarda una carga 'formativa' en tanto dota de valores teóricos y humanos a los estudiantes y procura una reflexión crítica en sus trabajos de investigación.

Esta práctica se ha validado en la mayoría todas las carreras y perfiles que existen en el recinto educativo cubano. Vale destacar que mediante ella ha acontecido un distanciamiento de la enseñanza de la Estética enfocada en su historicidad y en una visión tradicional de las artes visuales, para centrarse en procesos culturales y artísticos que convergen en el presente y viabilizan la vinculación de diferentes disciplinas como la psicología, la pedagogía, la sociología, la etnografía y la antropología (Véase a Cabrera 2007). Desde este sentido transdisciplinario, nos inclinamos por esta propuesta pedagógica que exige al educador nutrirse de la práctica simbólica que caracteriza a los procesos artísticos y visuales en la actualidad. En virtud de ello, propone una evaluación enfocada en que los conocimientos adquiridos en el curso se apliquen a la fundamentación teórica de un trabajo de diseño escénico. Así esta actividad final alcanza otro significado alejado de la reproducción de conocimiento, enfocándose en la reflexión y la crítica del mismo mediante su aplicación a los trabajo de los estudiantes de diseño.

La ID ha incentivado a los estudiantes a fundamentar teóricamente sus propuestas de tesis para la culminación de estudios de pregrado. También ha propiciado la presentación de ponencias relevantes en eventos y la mayoría de los trabajos se convierte en material de consulta por otros estudiantes.

Por tanto, en este texto analizamos el papel de la evaluación a partir de la ID, en la enseñanza-aprendizaje de la Estética. Para ello valora el papel de esta metodología y su pertinencia. Pese a que ha sido aplicada desde los años setenta del pasado siglo en otros ámbitos disciplinares, en las materias teóricas que conforman el currículo de Diseño Escénico esta metodología se adecua e implementa a través de un diálogo

1 La Universidad de las Artes, es la única de su tipo en Cuba, y a la vez que acoge a estudiantes de todas las provincias del país, también lo hace con jóvenes de diferentes latitudes del mundo que reciben una formación artística en dicho recinto académico. 
transdisciplinar (Véase Moraes, 2007). ${ }^{2}$ El texto se divide en tres partes: la primera resalta algunas notas que podrían tomarse como antecedentes de la ID, más tarde se analiza el concepto de formación y la incidencia de los valores estéticos como claves de esta propuesta, y por último, se valora la aplicación de esta metodología exponiendo algunos trabajos de jóvenes de la carrera de Diseño Escénico.

\section{La investigación dirigida, algunas notas para su contextualización}

La ID a la que hacemos referencia es también conocida como investigación orientada o guiada. Constituye un modelo de aprendizaje que hunde sus raíces en la vertiente constructivista del aprendizaje, del que sus principales exponentes son Jean Piaget y Lev Vygotsky. El primer autor centra su interés en la construcción del conocimiento mediante la interacción del medio, mientras que el segundo sustenta que el medio social viabiliza la reconstrucción interna del mismo en el proceso enseñanza-aprendizaje. Estas iniciativas apuntaron al desarrollo de metodologías de aprendizaje como la ABI que propone Ernest Boyer (1990). El autor retoma el aprendizaje por descubrimiento donde se indaga el estatus de la pregunta de investigación según su pertinencia para el trabajo que realiza el estudiante, que responde a la exposición reveladora del problema. Esto supone un análisis teórico-metodológico de los argumentos presentados en los textos, delimitando los antecedentes y actualidad del tema que supone una explicación informada de teorías. Además de la aplicación de ellas a problemas prácticos que finaliza con la escritura y defensa de un trabajo de investigación.

De esta manera se concibe una forma activa de aprender en la media que se entiende la construcción del conocimiento en su sentido gradual. En una descripción más certera del ABI, Mónica Peñaherrera (2014) sostiene que

El modelo de aprendizaje basado en la investigación es un modelo coherente con la didáctica actual, que se basa en la idea de que los estudiantes se apropien y construyan conocimientos cimentados en la experiencia práctica, el trabajo autónomo, el aprendizaje colaborativo y por descubrimiento, rubros fundamentales para alcanzar dominios en los aprendizajes, desarrollar conocimientos y actitudes para la innovación científica, tecnológica, humanística y social (Peñaherrera 2014: 207).

Autores como Heather Banchi y Randy Bell (2008) sostienen que la ABI suele expresarse en varios niveles, la indagación de confirmación, la estructurada, la guiada y la abierta. Se suele decir que la investigación abierta es la más exitosa, pero en ocasiones es rechazada por los profesores, debido a que los estudiantes son quienes formulan sus problemas y soluciones y en ocasiones el profesor podría invisibilizarse. Esta postura reformula el papel del profesor dentro del proceso, pero también supone mirar con otros ojos al estudiante como también portador de conocimiento.

Nuestra experiencia profundiza en la indagación guiada que entendemos como ID, debido a que según las experiencias obtenidas hemos introducido algunos cambios que involucran el papel de profesor, el estudiante y el programa. Ello demuestra la aceptación de esta estrategia de enseñanza en detrimento de otras. En ella el educador

2 Cuando hacemos referencia a este concepto coincidimos con M. C. Moraes quien dice que "la Transdisciplinariedad procura trascender las disciplinas en la tentativa de resolver lo que se queda más allá de las disciplinas. Así el conocimiento transdisciplinar ha de complementar los conocimientos disciplinarios, multidisciplinarios o interdisciplinarios" (Moraes, 2007: 37). 
va guiando el proceso de enseñanza formulando problemas de investigación asociados con el programa de Estética, del que los estudiantes van generando preguntas, acordes al interés de su trabajo de investigación. Esto indica que el profesor de esta materia teórica debe conocer los procesos creativos actuales para entablar un diálogo transdisciplinar con los estudiantes y con el contexto cultural. Por tanto

el educador ha de estar inmerso en esa realidad simbólica y no quedar al margen de ella, puesto que él ha de educar en el entramado sensible del porvenir [lo que le permitiría concebir las disciplinas teóricas y prácticas, de verlas en una interacción y una actualización estéticas enriquecedoras (Cabrera 2007:18-19).

Ello se observa en tres esferas importantes, el papel del profesor, del programa y del estudiante. Según las experiencias de la aplicación de esta propuesta el papel del educador en este proceso despertó posiciones discordantes que mostraban un apego a la enseñanza del programa de Estética vinculado a una perspectiva histórica. Esta condiciona la historia de la asignatura como eje central y desde una perspectiva tradicional. De modo que no considera la vinculación de la disciplina con expresiones, prácticas y discursos creativos actuales, así como su sentido transgresor que éste tiende a manifestar en la concepción misma de los procesos educativos. Si bien el sentido histórico ha de estar presente, éste no debe convertirse en el centro de atención porque según las experiencias anteriores establecen un divorcio entre la realidad simbólica actual que rodea al estudiante y las temáticas abordadas por la Estética desde una perspectiva tradicional, marcada por el sesgo histórico. Esto supone lo que señala Ramón Cabrera (2007) que "las disciplinas teóricas dejan un escaso espacio a las nuevas disciplinas y franjas de confluencias donde se presentan hibridados entre otras" (2007:17).

La principal demanda de los profesores de las carreras creativas a los de las disciplinas teóricas, entre las que ubicamos a la Estética, ha sido concebir un programa con una metodología que nutra al estudiante de herramientas para fundamentar su trabajo de diseño y enriquecerlo desde el punto de vista teórico. Bajo este reclamo se ha elaborado la propuesta de investigación dirigida o guiada como metodología que pretende satisfacer tal exigencia, a través de la forma de impartir el programa de la asignatura.

Esta práctica demanda un cambio si bien del programa, también de la forma de aplicarlo. El sesgo histórico no se abandona, más bien tiende a ocupar el eje de antecedente, mientras que el rector sería la problematización de fenómenos y temáticas vinculadas a los procesos creativos de interés para los estudiantes. Esto supone la construcción de una metodología que permita salirse del programa, modificarlo según las necesidades de los estudiantes y de la especialidad. El reto sería construir un programa adaptado a dichos reclamos que permita el diálogo transdisciplinar sin abandonar la formación estética de los estudiantes.

En esta propuesta el estudiante no juega un rol pasivo, más bien desarrolla la reflexión y la crítica teórica vinculada a su trabajo. Por ello se insiste en desarrollar la autogestión del estudiante, en el trabajo individual y en la formulación de preguntas relevantes como resultado de su experiencia. Si se piensa en un programa modificado y adaptado a los intereses de la carrera se está dando paso a un diálogo más cercano estudiante-profesor que se vale de la implementación de herramientas teóricas y de la solución de problemas a través de ellas.

Han existido casos en lo que los estudiantes no ha recibido con beneplácito dichos 
cambios y mayormente se debe al escaso interés e inutilidad que le dan a la investigación teórica. Estos son obstáculos generalmente vencidos mediante el interés que el profesor exprese por el trabajo de su discípulo demostrando otras formas en las que podría llevarse a cabo la investigación.

Si bien nuestra experiencia se ha enfocado en función de la enseñanza de la Estética, delimitamos el importante papel que en la ID cumple el concepto de formación estética. Partiendo de ello resulta imprescindible entender que la educación por el arte como la educación artística, aspira a la formación general del estudiante (Véase Cabrera 2007), por lo que resulta apremiante comprender el papel de la formación estética. Esta podría entenderse como una herramienta que permita articular la ID con las necesidades teóricas del Diseño Escénico.

\section{La formación estética como componente de la Investigación Dirigida}

La ID no podría pensarse al margen del concepto de "formación" por el carácter amplio y dinámico de su significado. Sus aspectos constitutivos han variado históricamente y continúan haciéndolo actualmente, ya que se asocia directamente a las necesidades sociales, económicas, políticas, culturales y de empleo. El concepto es asumido en el ámbito profesional, como una actividad educativa orientada a proporcionar conocimientos, habilidades, destrezas, desarrollar aptitudes y actitudes necesarias para un correcto desempeño profesional y laboral de los estudiantes. El pedagogo e investigador cubano Pedro Horruitiner Silva (2006) plantea:

El término formación, en la educación superior cubana, se emplea para caracterizar el proceso sustantivo desarrollado en las universidades con el objetivo de preparar integralmente al estudiante en una determinada carrera universitaria... (Horruitiner Silva 2006: 17).

Los antecedentes de esta formación están en el interés que la práctica humana le ha conferido a la premura de formar individuos sensibles a las necesidades de su época y de su contexto. Puede entenderse como un proceso donde intervienen aspectos esenciales marcados por necesidades del desarrollo social, cultural, de la época y de creación. Sin embargo, la debilidad de las estrategias formativas en general, y de las Estéticas en particular se hallan en que se desconectaron del hombre real, al fijar su atención en la finalidad y no en el proceso.

La propuesta de ID de la Estética en la Universidad de las Artes, mostró la ineficacia de las maneras de enseñar anteriormente y evidenció la necesidad de que se tuviera en cuenta la enseñanza mediante la investigación. Ella articulará las experiencias creativas de los estudiantes con la Teoría Estética y también proyectará el estado real de la formación estética, las vivencias y necesidades reales de los estudiantes. Este aspecto en particular, resulta esencial dado el carácter vivencial, individual y contextual de la experiencia estética. ${ }^{3}$ En concordancia con ello José Antonio Portuondo dijo que "[el] juego dialéctico entre el hombre y sus circunstancias, en virtud del cual aquel transforma a las circunstancias y, al hacerlo, se transforma a sí mismo" (Portuondo 1986: 20). Lo que significa que la formación estética debe entenderse a la luz de las problemáticas

3 Según Nicola Abbagnano, "la experiencia estética consistiría en proyectar en el objeto estético emociones propiamente humanas, o sea en 'dar a las cosas insensibles sentido y pasión', y como dijo Vico" (Abbagnano 1967: 396-397). 
actuales. En ella se le otorga un lugar significativo a las contradicciones que acontecen en la vida donde interviene no solo lo social, lo económico, lo político, lo cultural, sino las vivencias, preferencias y necesidades individuales de estos creadores en formación. Estos aspectos tienden a expresarse en las múltiples y variadas manifestaciones que se proyectan en el medio académico cubano. A estos aspectos tienden a dirigirse las investigaciones propuestas en el programa de estudios de la disciplina en el recinto universitario cubano.

Cuando hablamos de formación estética valoramos no solo lo que anhela la sociedad y la universidad, sino también el universo que rodea al estudiante. Entre sus ámbitos referidos destacan el contexto familiar, social, económico, tecnológico, así como también las relaciones que establecen con otras culturas, pueblo o naciones, de las cuales asumen también, muchos de sus paradigmas culturales y estéticos (visibles en formas de vestir, gesticular, hablar, comer, interrelacionarse, etc.). Tal y como sostiene Mayra Sánchez,

Los problemas estéticos están presentes en los más diversos imaginarios, en los más variados campos del conocimiento, en la propia realidad cotidiana en que se mueve el hombre, en las producciones y en el mercado, y no solo en el arte. Esto abre a la estética nuevas perspectivas. Tras el concepto de espíritu de la época se plantea hoy a la Estética un nuevo y extenso campo de influencia, lo cual por sí solo justifica el papel que le corresponde desempeñar en la universidad. La Estética se ha convertido en instrumento para salir airoso en una contienda donde no bastan razones. Son apremiantes los retos de un saber que profundice en la genealogía de los conceptos y nociones (Sánchez 2009: s/p).

En este sentido la evaluación debe solventar el estudio de temáticas estéticas que favorezcan el despliegue creativo, crítico y cuestionador de los estudiantes en las diferentes especialidades. También debe atender los intereses y perspectivas de los estudiantes. Esto supone entender la ID como un ejercicio en el que los estudiantes logren:

- Analizar el carácter procesual de esta disciplina manteniendo distante el sesgo hermético e inútil para su formación.

- Asumir el riesgo de distinguir sus trabajos de otros, pero también de entender sus perspectivas e intereses.

- Buscar lo igual en lo desigual, lo armónico en lo discrepante, lo conocido en lo que se sospecha, a partir de la comprensión de la formación estética, como aquello que no puede ser concebido de forma homogénea, ni hegemónica y se asuma con todas las gamas de contradicciones que le son propias a la existencia individual humana, aquí y ahora.

- Desarrollar capacidades para interrelacionarse y proyectarse hacia y desde la cultura, la política, la ideología, la economía, los problemas medioambientales y otros como necesidad incuestionable.

- Desarrollar capacidades de comunicación, de interrelaciones y empáticas con "el otro diferente", sin perder su identidad propia ni mucho menos desorientarse en un "relativismo" absolutizado donde "vale todo"; todo ello esencial para el desarrollo de sus proyectos creativos y de vida.

- Asumir la diversidad y multiplicidad de acciones diferentes.

- Desplegar aptitudes ético-estéticas ante la vida toda (capacidades, competitividad, idoneidad, disposición, etc.) y actitudes para enfrentar los problemas 
que se presentan (cualidades, maneras, formas, modos, etc.) que lo faculten para "vivir".

- Asuman no la formación estética con unos criterios de Estética que la supongan, no sólo en lo que se divulga y consume de bello, positivo, constructivo, seguro, etc., sino también en aspectos que se referencian como negativos, escatológicos o feos, reconstructivos, etc., pues es en esta complejidad donde lo que consideramos formación estética podría ser realmente útil por realista.

Estos aspectos se conectan sobremanera con la trascendencia de los valores éticos y estéticos como componentes de la formación estética.

\section{Los valores éticos en la formación estética}

En la ID es necesario considerar los entrecruzamientos teóricos para distinguir los valores estéticos de los éticos y lograr la factibilidad de la evaluación que se propone. Como antes se mencionó, con la ID los docentes deben pensar de manera abierta, flexible y dinámica, lo que les permitirá ampliar su visión de la realidad social en la cual se desenvuelven los estudios universitarios. Esta lógica demuestra la trascendencia de códigos y de valores estéticos. Estos últimos fueron asumidos en consonancia con las relaciones estéticas de cada contexto y temporalidad. Son estos valores estéticos los que los estudiantes asumen en el contexto cultural en el que les ha tocado vivir en la actualidad.

Como señala el destacado filósofo y esteta español Isidoro Reguera (1994):

Hoy en la actualidad e incluso [se suele] identificar o confundir la ética y la estética. Tanto una cosa como la otra se hacen la mayoría de las veces por motivos periféricos, como ya nadie tiene principios morales por los menos que valgan los estéticos, se dice, como ya no hay conciencia por los menos que haya buena educación... lo que sea, con tal de que el orden y la armonía -las 'maneras', características de estas disciplinas valorativas- se mantengan en cualquier lugar y aspecto (Reguera 1994: 13).

Sabiendo la importancia del concepto valor estético en esta investigación, partimos de los criterios del estudioso Stefan Morawski, quien propone entenderlo como

(...) un conjunto de cualidades tipificadoras de un objeto, acontecimiento..., manifiesto en y desde la experiencia apreciativa o estimativa sensible del sujeto y, por lo mismo, determinado social, histórica y culturalmente (Morawski 1977: 23).

Asumimos coincidiendo con José Ramón Fabelo (2001) que el valor es un conocimiento por significación, lo cual incluye la subjetividad en el propio contenido de lo que se evalúa. Ellos se ven afectados o no, por la incidencia de los más diversos mecanismos y estructuras sociales y culturales (a veces imperceptibles a simple vista). En este escenario, el profesor tiene la compleja tarea de asumirse como agente y portavoz crítico en la relación que, supone el mundo de los valores estéticos con el mundo social-cultural. Los valores estéticos están presentes en los más diversos espacios imaginarios e ideologías sociales. Por ello las conceptualizaciones del valor estético trascienden al interior de la enseñanza académica y se encuentran en ámbitos disímiles, así como en los proyectos culturales. 
No por casualidad Reguera en su libro El feliz absurdo de la ética (1994), ${ }^{4}$ hace referencia al papel que la sociedad y dentro de ella, el papel que la educación debe asignarle a los valores estéticos dentro de sus proyectos sociales y culturales. A partir de lo cual Jesús Martín-Barbero, en su artículo Nuevas visibilidades de lo cultural y nuevos regímenes de lo estético (2008) se refiera a que estas nuevas condiciones están:

[...] exigiéndonos una nueva noción de tiempo, correlato de una memoria activa y activadora del pasado, que nos permita desplegar los tiempos amarrados, obturados, por la memoria oficial y nos posibilite hacer estallar el historicismo que sutura al pasado como único depositario de los valores y esencias de la identidad nacional (Reguera 1994:35).

Lo esencial de los valores estéticos, es que pasen por el prisma individual de cada sujeto y que sean incorporados como parte de su accionar, donde realmente se gana o se pierde la batalla de la apropiación legítima o distorsionada de ellos. De modo que la universidad no puede enajenarse a estas condicionantes de las que beben estos valores. Por lo que, tener en cuenta la participación activa de los estudiantes, no solo como portadores de paradigmas culturales y estéticos, sino como sus consumidores, divulgadores, reproductores.

La formación y los valores estéticos son componentes y viabilizan la efectividad de la ID. La naturaleza axiológica de la Estética no debe entenderse solamente como atributo que tiene un objeto en sí mismo, ni tampoco como condición razonable, juiciosa o demostrativa del sujeto. Debe exaltarse el significado que adquieren para él las relaciones que establece con estos procesos, objetos o fenómenos existentes en la sociedad. Por lo que es ésta una relación de significación, donde la valoración estética conforma el imaginario y mapa socio-cultural del hombre contemporáneo.

Con la propuesta de evaluación a partir de la ID del programa de Estética de la Universidad de las Artes, los profesores-investigadores encargados de esta enseñanza, han comprobado resultados y experiencias novedosas con relación a la evaluación final de los trabajos de estudiantes. Las experiencias de la ID pasan a ser la razón principal o motivo en que se afianzan, y aseguran los contenidos de la Estética.

A partir de estas ideas se fomenta la indagación sobre temáticas que desde el ámbito de la Estética pudiera arrojar luz tanto a la impartición de la asignatura como a la investigación. En virtud de demostrar cómo se ha hecho visible la aproximación de la disciplina teórica en cuestión a la enseñanza de las artes en Cuba, nos permitimos tomar las experiencias de la investigación en el proceso de enseñanza-aprendizaje de la Estética en la especialidad de Diseño Escénico, como ejemplo palpable del objetivo principal de este trabajo.

\section{Estética y Diseño de frente. La investigación dirigida de la Estética y su im- pacto en la carrera de Diseño Escénico}

La enseñanza del Diseño Escénico en Cuba incluye la labor tanto de los maestros de la especialidad como de aquellos que imparten asignaturas teóricas que integran el

$4 \quad$ Una de las ideas que defiende el autor es que sólo desde la estética o desde la religión puede plantearse la ética. Considera que la ética es la práctica de la felicidad y no del bien, del deber o de la justicia como siempre ha sido concebida esta. Argumenta que la ética es la vida feliz: la realización de la felicidad o de la felicidad misma donde señala que la lógica señala el camino mientras que la estética lo cumple. En tanto que la ética intenta elevar al individuo la vida feliz, la religión intenta bajar a Dios a ella. 
currículo académico de la carrera. Al ser una práctica que requiere de aptitudes artísticas, también demanda de la conceptualización e investigación de algunos presupuestos que explican su devenir.

El programa de la carrera de Diseño Escénico en la Universidad de las Artes, está orientado en primera instancia a la práctica teatral y acoge Diseño de Vestuario, Maquillaje, Escenografía y Luces. Este currículo está integrando por asignaturas que complementan la visión de los procesos culturales, artísticos y teatrales básicos en la formación académica. Entre ellas destacan Historia del teatro, Historia del teatro latinoamericano, Historia del Arte, Estética, entre otras que acompañan el desarrollo de del estudiante. Todas son indispensables para su formación y la manera significativa en que se articulan con los intereses curriculares de la carrera.

La Estética como disciplina integrante de la carrera más allá de cumplir con un programa que toca diferentes problemáticas de la cultura, se ha readecuado a partir de los intereses de los estudiantes. Ello es posible debido a la exploración de la zona teórica que resulta vital para el diseñador en formación. Para este cometido se realizan algunos ejercicios que suponen un entrenamiento introspectivo de la obra en ejecución. Por tanto, se toman en cuenta presupuestos teóricos que acompañan al pensamiento estético contemporáneo.

La asignatura de Diseño Escénico, en la mayoría de los casos, se auxilia de un texto teatral a partir del cual el estudiante deberá trabajar para una escena o una obra. En el ejercicio se suele recrear la época, o idear otra en dependencia de su capacidad y de las posibilidades que le brinde el texto para transgredir espacios temporales. De esta forma la libertad creativa acompaña también el proceso de enseñanza-aprendizaje.

Otro de los aspectos que tributan al trabajo en cuestión es el empleo de materiales alternativos para concebir el vestuario, accesorios y la propia escenografía, contribuyendo a crear la atmósfera adecuada. De esta forma son visibles el empleo de piedras, cartón, nylon, cintas de video, madera, palmiche, rayos de bicicleta, metal entre otras, muchas veces acudiendo a diferentes técnicas entre las que destacan las del papier maché. En ocasiones esta técnica, da volumen visual a determinadas texturas, pero también, con ayuda del color imita disímiles materiales como el metal o la madera.

En este sentido se observan dos momentos importantes dentro de la creación. E1 primero de introspección, traducido en cómo la escena de una obra puede ubicarse en otro contexto dependiendo de las posibilidades creativas que brinda; y el segundo momento que aborda los elementos que validarían la obra en cuestión a partir de materiales con los que se trabajan tanto el diseño de vestuario como la escenografía.

Aunque las características del ejercicio se apoyan más en las potencialidades creativas del estudiante, la realización del mismo demanda de una fundamentación teórico-conceptual y es aquí donde la Estética entra a jugar un rol significativo con su propuesta de ID. Por lo que inspirándonos en el ABI de Ernest Boyer (1990) e introduciendo algunas adecuaciones que parten de la docencia del programa de Estética a partir del que formulamos un problema de investigación relacionado de manera general con la disciplina de Diseño Escénico. Estos últimos seleccionan una pregunta de investigación que supone la revisión de literatura y teorías buscando la relación estudiante-autores-textos. Después retomamos la aplicación de teorías a la praxis del diseño como fundamentación del mismo, para finalmente que el estudiante sea capaz de escribir un manuscrito crítico y reflexivo que expondrá como evaluación final de la asignatura.

Resulta imprescindible el acercamiento de estos dos saberes (Estética y Diseño) a 
partir de la necesidad de un diálogo transdisciplinar. Hoy es un hecho que la difusión de fronteras entre los ámbitos de la praxis artística, del diseño, la teoría estética y la filosofía se percibe como un síntoma cultural, artístico o académico que cuenta ya con antecedentes desde el pasado siglo. Esto hizo que las relaciones entre el arte, la vida y la cultura se hicieran cada vez más sólidas al tiempo que parecían confundirse, mezclarse e invisibilizar sus límites. Como ya señalaba Danto en su texto El final del arte (1995) las fronteras entre la pintura y el resto de las artes (la poesía y la interpretación, la música y la danza) se han hecho radicalmente inestables (Danto 1995: 3), y desde estos espacios de diálogo, es posible entonces pensar la Estética en su relación con el Diseño Escénico, salvando las diferencias pero insistiendo en una suerte de readecuación que responda a los intereses de la carrera y de los estudiantes.

Los exámenes finales de la asignatura suponen una reflexión teórica sobre una obra realizada para Diseño Escénico. Dicha creación artística mayoritariamente se relaciona con una temática abordada por la Estética entre las que pueden destacar: el arte y las nuevas tecnologías, la estetización, la espectacularidad, el kitsch, los imaginarios escénicos, relaciones arte-diseño, entre otros. Sin duda, éstas suelen ser las más representativas en el orden de evaluar su desarrollo teórico y aproximación a los conceptos que maneja el diseño escénico y que responden a los intereses de los estudiantes y de su asignatura rectora.

La selección de los casos paradigmáticos en la aplicación de la ID se fundamenta a partir de varios aspectos que competen la praxis (la complejidad de sus diseños mediante su producción) y la teoría (las formas en las que fundamentan su trabajo leyendo su entorno social y cultural y vinculándolo con estudios recientes correspondientes a la temática de interés. También en el interés que expresan por la investigación que genera en ellos la autogestión ya sea mediante la localización textos y en la relación de sus trabajos con problemáticas tratadas por la Estética. En ese proceso se resignifican los nexos entre las dos disciplinas mediante una crítica contextualizada en su trabajo y fundamentada el sentido del mismo. De manera que su argumento asume el valor conceptual de su propuesta que incluye vestuario, maquillaje, luces, escenografía y performance.

El primer caso que seleccionamos es el de Adrián Rodríguez que demuestra interés por la influencia de las nuevas tecnologías en la escena teatral. Su trabajo insiste en los modos en que los sujetos perciben, conciben y producen una puesta en escena donde conectan espacio-tiempo, cuerpo, objetos (Véase a Cotaimich 2004:5). Su pregunta de investigación ¿Cómo las nuevas tecnologías resignifican el sentido de la obra teatral? lo invita a dialogar con el texto La era postmedia de José Luis Brea. En su diálogo asume la implementación de las nuevas tecnologías en los procesos creativos como un componente de la puesta en escena contemporánea posibilitándole transgredir épocas y contextos, al tiempo que resignifica el mundo que vive el hombre actual. Bajo este cuestionamiento Adrián hace la escenografía de la pieza teatral Farsa y licencia de la Reina Castiza (Figura 1). Según las posibilidades que le brindaba la obra, Adrián emplea íconos y símbolos de los medios de comunicación como marcas de bebidas, firmas patrocinadoras de películas, fotografías de dibujos animados de Walt Disney, entre otros. La escenografía y las luces otorgan un ambiente sugerente que articula una vida íntima llevada a la espectacularidad donde lo público, lo privado y lo íntimo se trastocan incentivado por la publicidad y las tecnologías que hicieron de la vida del hombre un espectáculo cotidiano. Estas imágenes muestran la manera en que la tecnología 
influye en la percepción de la obra teatral proponiendo otra lectura sobre la obra que trae al contexto de la cultura actual.

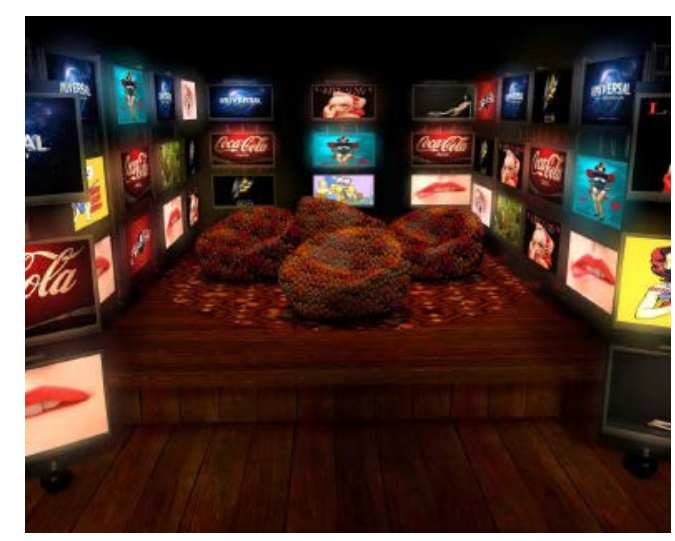

Figura 1. Diseño escenográfico para una escena de la obra Farsa y licencia de la Reina Castiza realizado por el estudiante de diseño Adrián Rodríguez

El fenómeno de lo intertextual también acompaña la reflexión de otros trabajos, como es el caso de la estudiante Alicia González, quien se inclinó por pensar su obra a partir de evidencias de lo intertextual en sus diseños. El discurso intertextual y performativo de "Realizando sueños" en la confluencia cada vez más cercana entre Arte y Diseño es la propuesta de la joven que dialoga con el texto de Linda Hutcheon, $\mathrm{La}$ política de la parodia postmoderna. A partir de él la joven cuestiona ¿cómo el collage y la intertextualidad ejercen un papel preponderante en los estilos de vestir que adopta el hombre en la sociedad actual? Su trabajo juega con la yuxtaposición de prendas supuestamente descontextualizadas que recrean una forma de vestir transgresora que podría ser aceptada o no para el público. Para ello la diseñadora organizó una pasarela que dialogaba constantemente con el público al trastocar su lugar y colocarlo en la posición de creador (Figura 2). En la acción, el público debía vestir maniquíes con determinadas objetos, accesorios o prendas que encontraban en el suelo que más tarde serían exhibidos en una pasarela. Esto supone una suerte de deconstrucción donde las prendas conformadas cobraban un nuevo significado a través de los materiales que las componían.

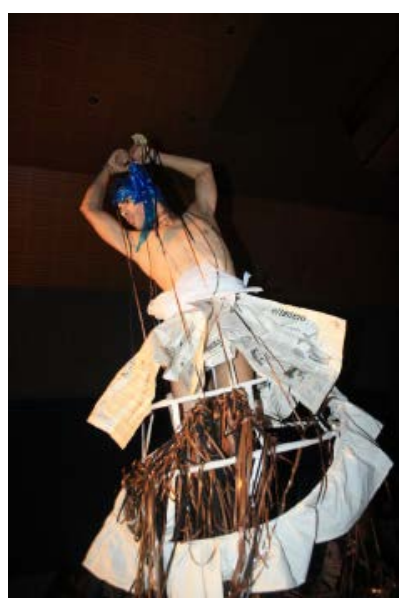

Figura 2. Diseño correspondiente al trabajo

Realizando sueño de Alicia González

Por su parte, Hugo A. Ruíz realiza un vestuario con materiales residuales como cintas de video, nylons, cartón, hojas de yagrumas, alambre, entre otros (Figura 3). E1 
mismo es expuesto en la pasarela Cuban's Trashions ocurrida en el marco del Festival Elsinor nombre que adopta el Festival de las Artes del recinto educativo en la facultad de Arte Teatral. Más allá de la factura con materiales alternativos la pregunta que guio el trabajo de Hugo fue ¿En qué media la sociedad condiciona la implementación de cánones estéticos que hacen de la vida un performance? Para ello Hugo tomó como eje central la significación del performance cotidiano al que está expuesto el sujeto actual. Esto suponía un diálogo con el texto Estética de lo performativo. A nivel teórico el joven reflexiona sobre la complejidad de su trabajo a partir de la escenificación. Con ella llama la atención hacia la difícil movilidad que trae consigo el cartón, que es el material básico de este diseño. Pero también alude a cómo los cánones sociales y de moda inmovilizan al ser humano en contra de su naturaleza. De ahí que el material básico que utiliza Hugo, proponga una reflexión teórica, social y práctica. Como antes se mencionó este diseño se realizó para la pasarela Cuban's Trashions, de ahí que los argumentos que use su creador denoten como un indicador sugerente lo performativo.

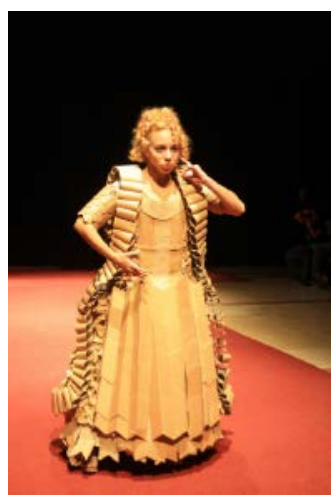

Figura 3. Diseño realizado por el estudiante de diseño Hugo A. Ruíz cuyo material primario es el cartón

Para algunos diseñadores el trabajo con estos materiales alternativos constituye una práctica revolucionaria que se ha ido reivindicando. Su uso en la confección de prendas de vestuario ha tenido varios seguidores al descubrir las innumerables posibilidades creativas que ofrecen estos materiales al descontextualizarlos de su finalidad común.

En Cuba dada la carencia de tejidos, los diseñadores han empleado como alternativa otros soportes y texturas siendo muy recurrente desde las últimas décadas del pasado siglo en el teatro cubano. Podría darse el caso que sin proponérselo el diseño escénico cubano haya explorado la creación a partir este tipo de materiales por la carencia de tejidos $\mathrm{u}$ otras texturas y no para promover una nueva forma de creación, aunque la segunda necesariamente quede implícita. Lo cierto es que este fenómeno se hace necesario seguirlo de cerca pues su desarrollo en dicho ámbito influye también en la enseñanza del diseño en Cuba.

Rolando Suárez fue otro de los estudiantes que ideó dos diseños para la pasarela Cuban's Trashions. La particularidad de su trabajo es su acercamiento con el metal. Aunque el diseño tiene la finalidad de exhibirse en pasarela y no como un trabajo para la asignatura de su carrera, Rolando decide fundamentar su obra partiendo de lo intertextual. Su pregunta de investigación para los dos casos seria ¿cómo lo intertextual y lo performativo le dan sentido a la puesta en escena de la vida misma? Para ello retoma el diálogo con el texto Estética de lo performativo de Erika Fischer-Lichte, donde este elemento completa la pieza como componente primordial. Si bien el intertextual se encuentra en la articulación de varios materiales y también de tendencias pasadas 


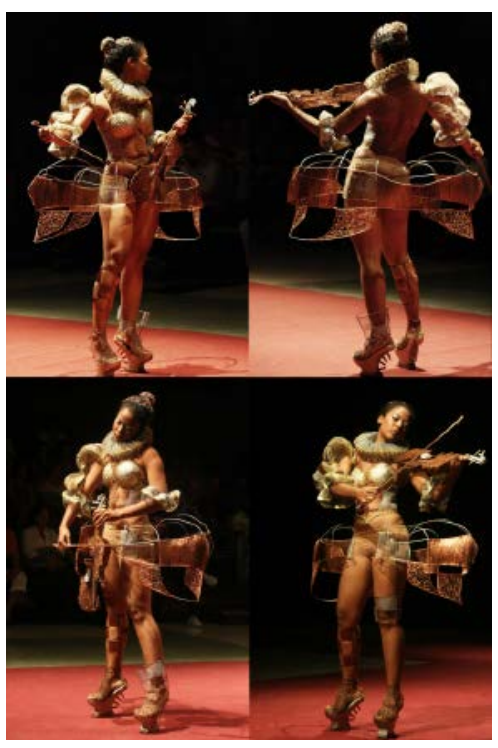

Figura 4. Diseño realizado por Rolando Rodríguez, quien toma como materiales básicos para su trabajo el hijo de alambre, rayos de bicicletas y otros materiales alternativos

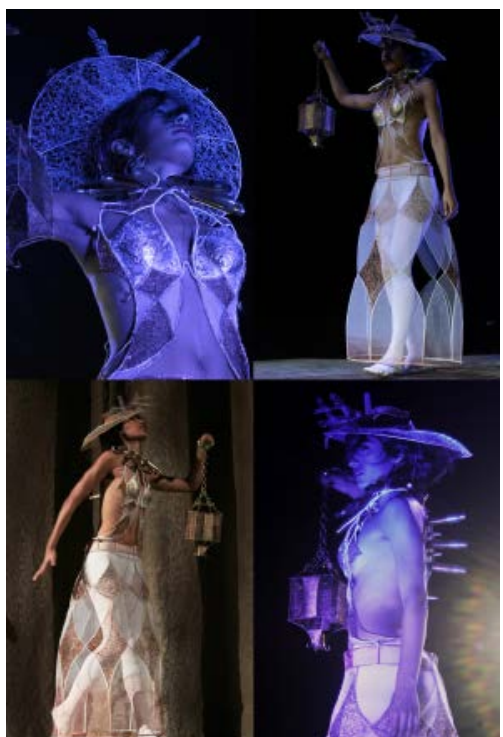

Figura 5. Diseño de Rolando Suarez realizados con metal, tejido de alambre y otros materiales que recrean la silueta del vestuario de la primera década del pasado siglo

y actuales de la moda, ella no cobraría sentido sin el acto de escenificación. A ello le añade valor el juego de luces al crear un ambiente particular que completa el diseño de vestuario, su representación o performance con la escenificación o el ambiente que se logra. Siendo así estos componentes argumentados desde la teoría estética y cultural fundamentan el trabajo de Rolando.

También analiza la mezcla de texturas como un elemento importante en la misma que está inspirada en un personaje ficticio que alude a un violín. Aunque la pieza se propone contar la historia del violín, el uso de materiales que invocan a dicho instrumento supone el realce de lo intertextual (Figura 4).

Su segundo trabajo se apropia de la silueta del vestido femenino de las dos primeras décadas del siglo XX. La misma se trabaja con diferentes materiales como el metal y el alambre, al que le incorpora como accesorios objetos que simulan un farol y algunos casquillos de balas que rodean el cuello y el dorso del maniquí (Figura 5). Este accesorio según el creador sugiere una conexión con los primeros veinte años del siglo pasado, donde estalla la Primera Guerra Mundial y la preocupación por la existencia humana, por el destino del hombre y de la humanidad, temas que se vuelve una constante. ${ }^{5}$

Estos son algunos ejemplos sobre los que puede trabajarse el diálogo disciplinar. No se trata que la asignatura se convierta en un eslabón más de la carrera, sino que contribuya a la formación del estudiante de diseño y le muestre distintas zonas de análisis que podrían visibilizarse en sus obras así como en eventos investigativos. El rol de la ID es fomentar si bien el interés por la indagación, también una formación estética para saber leer el medio y expresarlo en cada diseño para a su vez fundamentarlo teóricamente. 
Los trabajos seleccionados y analizados en este texto no se quedaron en clase sino que también se presentaron en una edición del Evento de Reflexión ${ }^{6}$ y de ALBUR. ${ }^{7}$ En estos espacios se presentan trabajos de corte filosófico y estético con la particularidad que permiten la articulación con saberes a su práctica visual como es el Diseño Escénico. Dichos eventos han contado con una buena acogida por parte del estudiantado al constituir un espacio donde mostrar y fundamentar su obra a partir de un trabajo investigativo previo. Son una buena oportunidad para socializar ideas y reflexionar acerca de los derroteros de la praxis del diseño. Aunque el evento cuenta con pocas ediciones constituye un referente para la investigación en artes desde los inicios de la carrera.

Estas pueden contarse también, como experiencias donde el diseño y el saber estético se articulan en virtud de fomentar la investigación académica entre los estudiantes. La ID permite este diálogo que constituye un elemento importante en la formación del estudiante de esa especialidad. Si bien esta se basa en la práctica más que en la teoría, la segunda resulta importante a la hora de encontrar y explotar otras zonas sobre las cuales se podría crear. Por ello es imprescindible que el estudiante conozca y sociabilice sus resultados investigativos no solo en el aula, sino también en eventos mediante la presentación de sus trabajos. También es imperiosa la necesidad de que el profesor se informe de las formas de creación, de las discusiones que en materia de diseño se llevan a cabo. Solo así el proceso de enseñanza-aprendizaje que propone la ID sería horizontal y dinámico.

\section{Conclusiones}

La evaluación a partir de la ID constituye una modalidad acertada para la enseñanza y aprendizaje de la Estética a la luz de sus problemas actuales. En ella la formación estética del estudiante universitario porque permite abordar los problemas de la cultura actual de una manera crítica y reflexiva. En este sentido el propósito de la disciplina Estética en la Universidad de las Artes ha sido acompañar los procesos creativos proporcionándoles a los estudiantes herramientas teóricas a través de la ID y algunos de los métodos aplicables en el aula.

Si bien la evaluación a partir de la ID manifiesta cercanías con la ABI que propone Boyer (1990), en nuestra experiencia fomenta en el estudiante la introspección de temáticas pertinentes para sus ámbitos y también para la cultura contemporánea. Además, le otorga la oportunidad de proponer temáticas relacionadas con sus intereses creativos a través de la revisión de fuentes bibliográficas como antecedentes del tema de interés. Así mismo se incentiva en el estudiante el sentido de la autogestión y del trabajo individual como elementos básicos de la propuesta de Boyer (1990). A ello se le suma la perspectiva constructivista dentro de la pedagogía en particular la vygotskiana que valida la propuesta de la concepción del conocimiento como objeto en construcción y no como dado, y que también apunta a la cualidad de investigar la realidad en la que se desarrolla el proceso de enseñanza-aprendizaje. Esto le otorga un rol activo y responsable al estudiante. Además, permite al profesor-investigador de Estética incli-

6 Evento de investigación estético-filosófica organizado por los profesores-investigadores del Departamento de Filosofía de la Universidad de las Artes. En él los estudiantes presentan avances de sus trabajos creativos articulándolos con una teoría que fundamente sus trabajos.

7 Evento teórico organizado por los jefes de departamento de cada facultad cuyo objetivo es dar a conocer y reflexionar sobre la praxis artística contemporánea. 
narse hacia otras zonas antes invisibilizadas por esta disciplina lo cual demanda de su información y conocimiento acerca de la realidad simbólica que nutre al estudiante, así como de las discusiones y temas de la especialidad de Diseño Escénico.

De manera que la aplicación de la evaluación a partir de la ID no solo demanda del esfuerzo del estudiante, sino también del profesor, quien debe de ser muy cuidadoso de los contenidos y temáticas que propone y desarrolla en clases. Más bien en este proceso no solo se observa el aprendizaje por parte del alumno, sino también del profesor. De modo que pese a algunos obstáculos expuestos en la primera parte de este texto, este tipo de evaluación visibiliza la capacidad de la asignatura de actualizarse y trascender.

\section{Bibliografía}

Abbagnano, N. 1967. Diccionario filosófico. La Habana: Editorial Instituto del Libro.

Banchi, H. \& Bell, R. 2008. The Many Levels of Inquiry. Science and Children, 46(2), 26-29, October 2008.

Boyer, E. 1990. Scholarship Reconsidered: Priorities of the Prefessoriate. Pircenton:Carnegie Fundation for Avancement of Teaching.

Brea, J. L. 2004 La Era Postmedia. Acción comunicativa, prácticas (post)artísticas y dispositivos neomediales. Consultado en http://www.laeraposmedia.net. y http://www. joseluisbrea.net (30-9-2010).

— 2004: El tercer Umbral. Estatuto de las prácticas artísticas en la era del capitalismo cultural. CendeaC. Consultado de http:// www.joseluisbrea.net (30-9-2010).

Cabrera, R. 1998. Escuela, imagen y medio total. Nuevo León: Universidad Autónoma de Nuevo León. Facultad de artes Visuales.

— , 2007. "La formación del educador artístico". Una vocación humana permanente". Artes, La Revista. N¹4, V.7. Julio-Diciembre.

Cotaimich, V. 2004. "El impacto de las nuevas tecnologías en la puesta en escena. La Estética Dialógica como desafío estético, poético y político. Generalidades acerca de la integración de nuevas tecnologías en la escena teatral". En línea: <.ar/jornadas04/ponencias/cotaimich.pdf>. Consultado el 11 de abril de 2009.

Danto, A. 1995. "El final del Arte". El Pasante (formato digital), 22-23.

Fabelo, J. 2001. Los valores y los desafios actuales. Universidad Autónoma de Puebla. México. I. Filosofía. Habana.

Fischer-Lichte, E. 2011. Estética de lo performativo. Abada Editores, S.L., Madrid.

Horruitiner Silva, P. 2006. La Universidad Cubana: el modelo de formación. La Habana: Félix Varela.

Hutcheon, L. 1993. "La política de la parodia postmoderna". Criterios, La Habana.

Martín-Barbero, J. 2008. Nuevas visibilidades de lo cultural y nuevos regímenes de lo estético. La Puerta FBA; (3) Gedisa.

Moraes, M.C.: Interdisciplinariedad y transdisciplinariedad en la educación. Fundamentos ontológicos y epistemológicos, problemas y prácticas. En Torre, S., Pujol, M. A., Sanz. G. (Coords) (2007): Transdisciplinariedad y Ecoformación. Madrid: Universitas. p. 27-44.

Morawski, S. 1979. Fundamentos de estética. La Habana: Arte y Literatura

Peñaherrera, M., Chiluiza, K. y Ortiz, A. 2014. "Inclusión del Aprendizaje Basado en Investigación (ABI) como práctica pedagógica en el diseño de programas de postgrados en Ecuador. Elaboración de una propuesta". Journal for Educators, Teachers 
and Trainers, Vol. 5(2), pp. $204-220$.

Portuondo, J. A. 1986. Ensayos de Estética y de Teoría Literaria. La Habana: Letras Cubanas.

Reguera, I. 1994. El feliz absurdo de la ética. (El Wittgenstein místico) Madrid: Tecno, S.A. Juan Ignacio Luca de Tena, 15 -28027//. Reedición (2004).

Sánchez, M. 2009. "Repensar la estética". Paper presented at the Jornada XXV Aniversario del Instituto de Filosofia, Instituto de Filosofia. Sin publicar.

Vygotsky, L.S. 1962. Thought and Language, Cambridge, MA: MIT Press. 


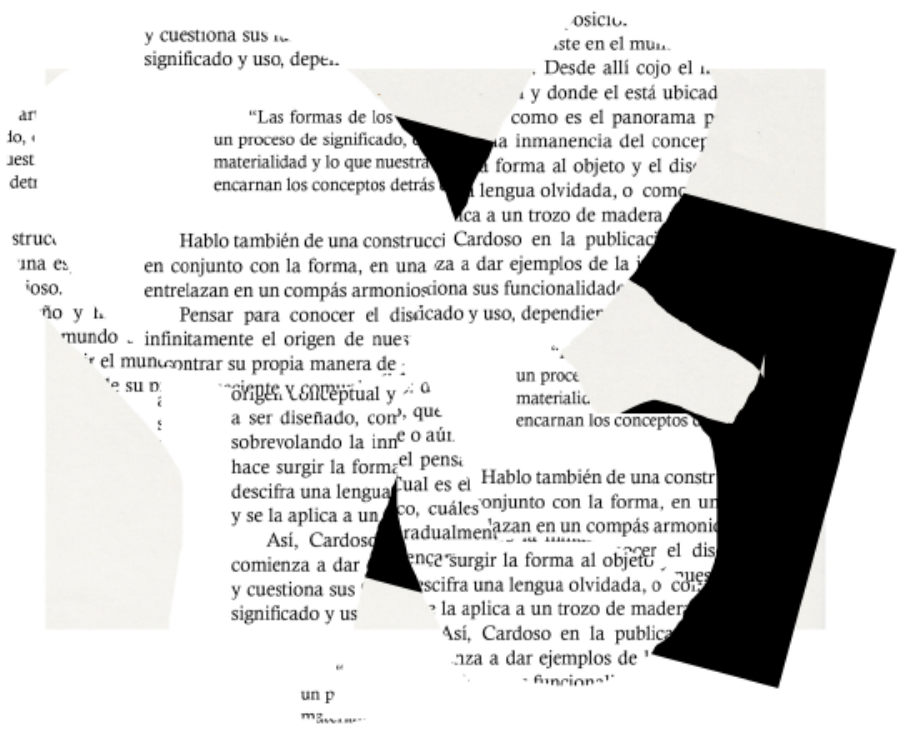

"Lo impreso exige una humildad de espíritu por cuya falta muchas de las bellas artes se tambalean ahora en experimentos de autoconciencia y sensiblería. No hay nada simple ni aburrido en lograr una página transparente. La ostentación vulgar es el doble de fácil que la disciplina".

Beatrice Warde, The Crystal Goblet, or why printings should be invisible (1930)

"El diseño que es objetivo, comprometido con el bien común, bien compuesto y delicado, constituye la base del comportamiento democrático".

Josef Müller-Brockmann, Grid and Design Philosophy (1981) 

EDITA

\section{SEyTA.}

SOCIEDAD ESPAÑLAA
DE ESTETICA Y TEORIA DE LAS ARTES

CON LA COLABORACIÓN DE

\begin{tabular}{|c|c|c|}
\hline 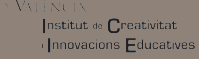 & $\begin{array}{l}\text { VNIVIRSIIN } \\
\text { II) VIIINCL Departament de Filosofia }\end{array}$ & 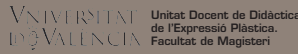 \\
\hline $\begin{array}{l}\text { ESTETICA } \\
\text { FLOSOFIA }\end{array}$ & 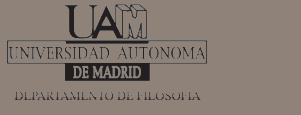 & $\begin{array}{l}\text { UAB } \\
\begin{array}{l}\text { Universitat Autònoma } \\
\text { de Barcelona }\end{array}\end{array}$ \\
\hline
\end{tabular}

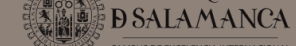

https://ojs.uv.es/index.php/LAOCOONTE/index 